\title{
Finer specialization in obstetrics and gynaecology do not benefit the general public
}

\author{
Pradeep de Silva ${ }^{a}$
}

It's been a great honor that have been bestowed upon me by the members of Sri Lanka College of Obstetricians and Gynaecologists to have duly elected me to lead you through the year 2021 as the $35^{\text {th }}$ president of this esteemed professional college.

My career in the SLCOG started as an unexpected meeting with eminent Obstetrician and Gynaecologist late Dr. Devika Suriyawansa at Wijerama House who offered me a post in the council of Prof Jayantha Jayawardana in 2006.

My speech today though brief would focus on two areas of my profession. First part focuses on why due care needs to be provided at our labour wards and second part is about why we should keep the art of providing general obstetrics and gynaecology services to our fellow citizens.

Ninety nine percent of Sri Lankan citizens are born in health institutions belonging to the government. Of this, $70 \%$ occur in labour wards of the government hospitals. (others are caesarean deliveries in operating theaters).
A woman in labour is cared in labour units, in most circumstances less than 12 hours. At the end of her stay in the labour suite she gives birth to a child of hers. On a larger context she gives a precious gift to the society.

These gifts were us, the big people who have gathered here today. We came out wrapped in a piece of cotton cloth placed in between the legs of our mothers wheeled to ward from the labour suites. Individually, none of us one can remember such journey.

Don't you think that we have a duty, a moral obligation to provide affordable yet the very best standard of care to the place that gave us life?

The very best which I mean come in two forms.

1. Human resources

2. Equipment

Human resources in a labour ward can be categorized into medical, nursing, midwifery and auxiliary staff.

Sri Lanka Journal of Obstetrics and Gynaecology 2021; 43: 1-4

DOI: http://doi.org/10.4038/sljog.v43i1.7991

a Consultant Obstetrician and Gynaecologist, Colombo North Teaching Hospital, Ragama, Sri Lanka.

Correspondence: PS, e-mail: madiweakotte@gmail.com

Received $28^{\text {th }}$ February 2021

Accepted $1^{\text {st }}$ March 2021

iD https://orcid.org/0000-0002-7899-4901

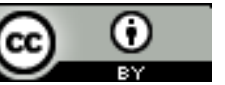

This is an open-access article distributed under the terms of the Creative Commons Attribution 4.0 International License, which permits unrestricted use, distribution and reproduction in any medium provided the original author and source are credited. 
Other than the auxiliary staff all others are specifically trained on caring for pregnancy.

Though midwives and midwifery qualified nurses are to be competent in monitoring the labour, they function at present mainly for monitoring the heart sounds of the foetus, maintaining the partogram with the data on progress provided by the medical staff, administering medication as prescribed and to support the mechanical delivery of the baby.

Let me focus on the component about the medical staff.

Labour ward is a unit functioning $24 \times 7$. It needs medical personnel on site throughout $24 \times 7$. Resident medical officer is the king pin of this engine of care. No argument that, this doctor should be knowledgeable on the subject.

Let's assume this part of knowledge is tested at MBBS. But I doubt it, as I can see the clinical curriculum to be bare 11 hours of lectures on the subject of obstetrics in some universities. Clinical component of obstetrics and gynaecology now have reduced to two weeks of ward visits due to administrative factors and further squeezed to one week of clinical work due to covid infection. I wonder where the guardians of standards of medical education are at this moment.

My point here is not to dwell on the undergraduate medical education but to remind this audience that we delegate this task of being the resident in labour wards to an Intern House Officer just after MBBS.

If post-partum haemorrhage (that is bleeding after the birth of the child) is the major cause for the maternal death in Sri Lanka. Please understand that PPH originate in the labour ward.

In my experience as a carer who has worked in all provinces other than northern province of Sri Lanka, good appropriate care in labour wards can reduce this factor as a cause of death to near zero.

You can't expect this service from an intern. I reiterate that You can't expect this service from an intern.

Most, but not all immediate post delivery problems of babies can be prevented by early identification of deviations of labour progress by an experienced doctor not by an intern with no experience. This too is very important to family, society and the government.

About the labour ward let me revel you a top secret. In Sri Lanka we do not allow administering medication as an injection to numb the parts of our body to nurses and midwives. Therefore, we perform a cut at the entry to vagina called an episiotomy at the very moment of the escape of babies head out of the birth canal.

As there is no medical officer cover in the labour ward $24 \times 7$ even in the year 2020 we perform this cut with no anaesthesia. That is the scream you hear form the labour ward.

This fact is one cause for urban women resorting to elective caesarean delivery which has a unmeasurable effect on the society in long term.

We need to correct this barbarism right now.

The cut we give is repaired by the most junior of the doctors of the team, that is an intern with no experience. Inappropriate choice of suture material add insult to injury.

We destroy the only pleasure ordinary Sri Lankan have by not properly repairing the episiotomy cut.

When talking about equipment providing Entonox gas to ease the pain, a good delivery bed to lie comfortably in labour and a spot lamp manufactured in Sri Lanka can't be a difficult task.

I was fortunate to get the attention of the Madam Shiranthi Rajapakse through my friend Prof. Dodampahala on this unspoken misery of ordinary women which I just described.

Madam really felt about this as a woman and a mother. That is why I called her mother of our hearts.

Madam pioneered a process with a meeting in Temple Trees on 26/10/2020 which she arranged for us to meet our Hon Minister. Additional Secretary Dr Somathunga represented the Secretary of Health in this meeting at Temple Trees. Dr Ajanthan represented the College of Pediatricians. With the blessing of the ladies present there was an agreement arrived to correct this vacuum of not providing due medical cover to labour wards in stages in next few years. 
I hope that the official commitment agreed upon, for this would be adhered to and we will see medical officers appointed to cover labour units of teaching and provincial general hospitals become a reality in the next post intern list of appointments.

As lowering of maternal mortality and morbidity are declared as the first point in the "Saubhgyayedekma" that is vistas of prosperity and splendor in the gazette. I give my full assurance to the dignitaries gracing this occasion, that if we do this with little more support, we will be able to halve the maternal death rate from present rate which is stagnant for 10 years at the rate of 32 maternal deaths per 100,000 live births.

We appoint medical officers in excess to some hospitals and units. Let me give an example of a rural hospital in North western province starting with letter "R".

With knowledge on numbers of the surrounding locality we appoint 7 medical officers to such place but at a given time only one to two officers would physically work there.

No advisory board is set up in the Ministry for recommendation on appointments.

To understand, the difference between theory of appointments and practice of getting work done for the money we pay from public funds an advisory board of practicing senior clinicians is a must.

As a person with long history of trade union work I say, this advisory board should not be intimidated by trade unionism though they should be given chances for written representation.

Once I was seated in the front row when at that time Director of the Post Graduate Institute of Medicine who delivered a speech at the Foundation Institute was justifying the creation of cardiologists from physicians and electro-cardio physiologists from cardiologists.

But I understood that he missed a big part of facts on the argument he was tabling.

If you come to a decision with no perusal of all facts available it is a conjecture not a conclusion.

Whatever, the finer specialties created must be practically relevant. It's idea should be to benefit the society at large. Just because some finer specialties are relevant nowadays such as orthopedics, nephrology and neonatology for various reasons, we must not generalize such.

Generalizing such means, that we are trying to compare apples with oranges.

Creation of a finer specialty in Sri Lanka is not paralleled to what occur in United Kingdom, Australia or United States.

In United Kingdom as far as I know there are no such degree programs. Therein UK after common basic postgraduate qualification, following a specialized Royal College program or a Trust approved Fellowship program makes one eligible to apply for a post which we in Sri Lanka have taken upside down.

In Sri Lanka finer specialization is done by introducing a prospectus to the Post Graduate Institute of Medicine by a board of study. This process is not smooth and influential people can by-pass the checks and balances put on the process. I am correct if I say some finer specialties are created to fit a profile of a known person or a unit rather than the national requirement. Here we create a person and then make the post fitting him.

If we are to follow the present model of sub specialization though I have reservations, in my opinion it should be the DGHS who should request the creation of a finer specialty if he thinks it is necessary for national service.

What happens if finer specialties are hypothetically created on maternal medicine (as tried some years back) and a specialty on foetal medicine?

Moment a finer specialty is created you imply in legal terms that any other person without such qualification is not the best to care for such illness.

Let me site an example of a pregnant woman with high blood pressure. This lady would be required to be attended by three specialists for her care, namely a generalist who will do the delivery, a maternal medicine specialist who will treat the part of the blood pressure and the foetal specialist who would be needed to monitor the foetus for its health.

In practice these three specialists will not meet with each other in the presence of the patient other than for 
a reality television show in Sri Lanka. Not even in private sector let alone in the Government Hospital.

In the presence of specialists in finer areas of such there is a legal danger for caring for similar pregnancy by an ordinary generalist by him or herself as it is always possible to have a bad outcome for mother and or the baby.

Let me tell you that at present all these areas of care which I hypothesized, of being made subspecialized are been taught and tested by the stream for MD in Obstetrics and Gynaecology in which I was the Chief Examiner 2020 with no deficiencies noted in the care. So, it is questionable to think about the need to do otherwise.

I will draw your attention to a case where a judge questioning a surgeon board certified with interest in breast attending a gangrenous bowel which resulted in death of a patient. Can anyone say due best care has been given?

It is logical that such patient should be cared by a surgeon with interest in bowel. It will be very difficult for the respondent of such case to hold.

It is because of this, that the finer specialization in Obstetrics and Gynecology other than the two existing streams which do not benefit the general public for the money they spent was declined by the Sri Lanka College of Obstetricians and Gynaecologists since 2018.

In 2018 SLCOG under the leadership of Prof Deepal Weerasekara informed the Director General of Health Services at that time about our membership's vehement opposition to further divide our specialty. DGHS then took the wise decision to discard such creation.

As in any argument the proponents may argue in favor.
What they say though factually correct in a smaller narrative, would be unreasonable in application context.

As long as great majority of members of the Sri Lanka College of Obstetricians and Gynaecologists decline the concept of any additional fields of finer specialization in our field, I hope that the 2021 council of Sri Lanka College of Obstetricians and Gynaecologists would stand by rejecting any more fields of sub specialization in Obstetrics and Gynaecology.

Proposal that the Sri Lanka College of Obstetricians and Gynaecologists is presenting is overcome any skill that its members wish to acquire is to develop fellowship programs to suit the demand as done in United Kingdom where we most had our training.

Sri Lanka College of Obstetricians and Gynaecologists hope to develop a pathway for such.

Regarding research, I have given the reigns of development of research and fellowship programs in SLCOG to the Chairman of the National Research Council who is a member of us as he is the member with most internationally accepted citations in our association. I am sure that he will deliver the results.

With this I would like to conclude my speech by appreciating the support given by my loving wife Sonali and two children for my service as an Obstetrician and Gynaecologist in my country bearing my absence for a good part of their lives, which I can't catch up.

I am sorry for my mother who could not come to participate in this occasion as she is recovering after a fall resulting in fracture of her hip.

I must remember my late father who encouraged unhindered free thinking to me as his son from my young days.

Thank you very much for patient listening. 